\title{
The Influence of Challenge on Cathepsin B and D Expression Patterns in the Silkworm Bombyx mori L.
}

\author{
Feng-Yao Wu, Feng-Ming Zou, Jun-Qiang Jia ${ }^{1}$, Sheng-Peng Wang ${ }^{1}$, Guo-Zheng Zhang ${ }^{1}$, Xi-Jie Guo ${ }^{1}$, and \\ Zhong-Zheng Gui ${ }^{1, *}$ \\ Jiangsu University of Science and Technology, Zhenjiang 212018, China \\ ${ }^{1}$ Sericultural Research Institute, Chinese Academy of Agricultural Sciences, Zhenjiang 212018, China
}

(Received 30 June 2011; Accepted 05 September 2011)

Cathepsins are well-characterized proteases that are ubiquitously expressed in lysosomes. Previous work revealed that Bombyx mori cathepsins $B$ and $D$ are expressed in the fat body and undergo decomposition during larval-pupal metamorphosis. Quantitative RTPCR was performed to detect cathepsin gene expression at the transcription level when challenged by $B$. mori nuclear polyhedrosis virus (BmNPV), temperature and hormones (20-hydroxyecdysone (20E) and juvenile hormone analogue (JHA)). mRNAs encoding cathepsins $B$ and $D$ were significantly enhanced after the larvae were infected with BmNPV, and the peak of the induction appeared at 1 day before spinning. This attenuated the inducing effect on cathepsin expression caused by infection. Temperature shock induced cathepsin expression at the later stage of the $5^{\text {th }}$ instar, and transcription levels varied with development stage and temperature. Cathepsin B and D mRNA expression in the fat body were significantly induced by JHA at the day before spinning, and with $20 \mathrm{E}$, the expression reached a peak at the last day of the $5^{\text {th }}$ instar. Cathepsin B and D mRNA expression exhibited detectable changes post-treatment, without significant differences between or among the hormone concentrations.

Key words: Bombyx mori, Cathepsin B and D, Expression, BmNPV, Hormones, Temperature

\footnotetext{
*To whom the correspondence addressed Jiangsu University of Science and Technology, Zhenjiang 212018, China.

Tel: +86-511-8561-6716; E-mail: srizzgui@hotmail.com
}

\section{Introduction}

Cathepsins are ubiquitous lysosomal enzymes and can be divided into three subgroups according to their active-site amino acid (i.e., cysteine: B, C, H, F, K, L, O, S, V, W cathepsins; aspartic acid: D and E cathepsins; and serine: $G$ cathepsins) (Duve, 1983). Proteases of the cathepsin family are among the most studied lysosomal hydrolases that degrade proteins in lysosomes at an acidic $\mathrm{pH}$. Apart from their function in general protein turnover, housekeeping, and protein processing, knock-out experiments have revealed that cathepsins perform specific functions in mammals, such as neovascularization of endothelial progenitor cells (Urbich et al., 2005), antigen presentation (Nakagawa et al., 1998), cell growth (Saftig et al., 1995), tissue homeostasis (Nakanishi et al., 2001) and apoptosis (Fehrenbacher and Jaattela, 2005). Cathepsin gene transcriptional up-regulation has been reported in immunestimulated Drosophila and Glossina morsitans morsitans (De Gregorio et al., 2001; Attardo et al., 2006). Several lines of evidence suggest that cathepsins are involved in insect immune responses (Zhong et al., 2001; Ahn and Keyan, 2009).

Cathepsin D is a proteolytic enzyme of lysosomes, and like most of the lysosomal enzymes, it usually occurs as a glycoprotein. This protease has acidic $\mathrm{pH}$ optima ranging from $\mathrm{pH} 3$ to 5 and relies on two aspartic acid residues for catalysis. In insects, cathepsin D is implicated in physiological processes such as vitellogenin production and degradation in mosquitoes (Cho and Raikhel, 1992), digestion (Silva and Xavier-Filho, 1991; Brunelle et al., 1999), fat body histolysis in Ceratitis capitata (Rabossi et al., 2004), and programmed cell death for the larval-pupal transformation in Bombyx mori (Gui et al., 2006). The cathepsin $\mathrm{D}$ enzyme also acts in blood meal digestion in ectoparasitic mites and ticks (Boldbaatar et al., 2006). 
Cathepsin B is a cysteine proteinase normally localized to lysosomes. It has been reported in numerous insects and can take part in physiological processes such as ontogenesis, and tissue differentiation through its nonspecific proteolytic function (Carnevali et al., 2001; Shompole and Jasmer, 2001), as well as histolysis and histogenesis during metamorphosis (Lee et al., 2009). Cathepsin B participates in decomposition during the larval-pupal metamorphosis of B. mori (Shiba et al., 2001; $\mathrm{Xu}$ and Kawasaki, 2001) and in the decomposition of the larval fat body during metamorphosis of the flesh fly, Sarcophaga peregrina (Takahashi et al., 1993).

Our recent study of B. mori metamorphosis showed that both cathepsin $\mathrm{B}$ and $\mathrm{D}$ are involved in fat body histolysis during larval-pupal transformation (Gui et al., 2006; Lee et al., 2009). Nonetheless, the biological significance of these enzymes projects far beyond metamorphosis. Because cathepsins act in insect immunity, we posed the hypothesis that cathepsins act in insect responses to other challenges as well. In this study, we investigated the expression patterns of $B$. mori cathepsin $\mathrm{B}$ and $\mathrm{D}$ during the last instar phase when challenged by $B$. mori nuclear polyhedrosis virus (BmNPV), temperature and insect hormones (20-hydroxyecdysone (20E) and juvenile hormone analogue (JHA) using fluorescence quantitative real-time PCR.

\section{Materials and Methods}

\section{Insects}

The larvae of the silkworm, B. mori, used in this study were F1 hybrid Suzhen $\times$ Chunguang and were supplied by the Sericultural Research Institute, Chinese Academy of Agricultural Science, Zhenjiang city, China. Silkworms were reared on fresh mulberry leaves at $25^{\circ} \mathrm{C}$ with $75 \pm$ $5 \%$ relative humidity and a 12 -h light:12-h dark photoperiod.

\section{Treatment of $B$. mori larvae}

\section{B. mori nuclear polyhedrosis virus (BmNPV) infection}

Two hundred larvae for each treatment were used. BmNPV $\left(5 \times 10^{7}\right.$ polyhedra/ml and $10 \times 10^{7}$ polyhedra/ $\mathrm{ml}$ ) was administered with fresh mulberry leaves to fifth instar larvae from $0 \mathrm{~h}$ to $24 \mathrm{~h}$.

\section{Temperature treatment}

For temperature treatment, B. mori larvae were divided into three groups and exposed to three temperatures, $22^{\circ} \mathrm{C}$, $25^{\circ} \mathrm{C}$ and $28^{\circ} \mathrm{C}$, from day 1 of the fifth instar to spinning, typically about 8 days.

\section{Hormone exposure}

Hormonal exposure treatment was applied as described previously (Gui et al., 2009). 20-Hydroxyecdysone (20E, Sigma) was dissolved in distilled water for stock concentration of $1 \mathrm{mg} / \mathrm{ml}$. Concentrations of $0.5 \mu \mathrm{g} / \mu \mathrm{l}, 1.0 \mu \mathrm{g} / \mu \mathrm{l}$ and $2.0 \mu \mathrm{g} / \mu \mathrm{l}$ of $20 \mathrm{E}$ were injected into $B$. mori larvae on day 3 of the fifth instar. Concentrations of $2 \mu \mathrm{g} / \mu \mathrm{l}$ and $4 \mu \mathrm{g} / \mathrm{il}$ of a JHA, fenoxycarb (Sankyo, Japan), dissolved in acetone were applied topically to larvae on day 3 of the fifth instar with a micropipette along the dorsal midline.

\section{Tissue collection and RNA extraction}

The fat bodies from all treated larvae were collected on ice at 1-day intervals post-treatment and washed twice with PBS (140 mM NaCl, $27 \mathrm{mM} \mathrm{KCl,} 8 \mathrm{mM} \mathrm{Na}_{2} \mathrm{HPO}_{4}$ and $\left.1.5 \mathrm{mM} \mathrm{KH}_{2} \mathrm{PO}_{4}, \mathrm{pH} 6.5\right)$. The homogenates were centrifuged at $10,000 \times \mathrm{g}$ for $20 \mathrm{~min}$, and the pellets were discarded. Total RNA was extracted from fat bodies using TRIzol (GENERAY, China) according to the manufacturer's instructions. Total RNA was dissolved in water treated with diethyl pyrocarbonate (DEPC), and the concentration was measured using a UV-1601 spectrophotometer (Shimadzu, Kyoto, Japan). DNA within RNA samples was digested with RNase-free DNase I. The quality of RNA was analyzed on $1.0 \%$ agarose gels.

\section{Reverse transcription and primer design}

RT-PCR was performed as previously described (Zou et al., 2011). The first strand of cDNA was synthesized using PrimerScript ${ }^{\mathrm{TM}}$ RT Enzyme Mix I Reverse Transcriptase following the manufacturer's instructions (TaKaRa Code: DRR037A, China). Briefly, reverse transcription was carried out in $0.65-\mathrm{ml}$ RNase-free tubes under optimized conditions in a DNA Thermal Cycler 480 (PerkinElmer). Equal amounts of total RNA (500 ng) from each sample were used for these reactions. Each reaction was performed at $37^{\circ} \mathrm{C}$ for $15 \mathrm{~min}$ and $85^{\circ} \mathrm{C}$ for 5 $\mathrm{s}$ in a total volume of $10 \mu 1$ containing $2 \mu 15 \times$ PrimeScript TM Buffer, $0.5 \mu 1$ PrimeScript $^{\mathrm{TM}}$ RT Enzyme Mix I, $0.5 \mu \mathrm{l}$ of $50 \mathrm{~mol} / 1$ OligodT primer, $1 \mu \mathrm{l}$ total RNA and RNase-free $\mathrm{H}_{2} \mathrm{O}$. The following specific primers for cathepsins $\mathrm{B}$ and $\mathrm{D}$ were designed and prepared according to the available information for these specific genes (Gui et al., 2006; Lee et al., 2009). The primers for B. mori cathepsin B (5'- AACATCACGTACCCGGCAACA -3' and 5'- CGCGGATGTGGTCTTCGTCT -3') amplified a 159-bp product (642-800); the primers for $B$. mori cathepsin D (5'- ATTTCTCATAAGCAAGTCGC -3' and 5'AGTGGGTTCTCGCAGTTTT -3') amplified a 146-bp product (97-242). The primers for the housekeeping gene actinA3 (5'- ATGGGACAGAAGGACTCGTA -3' and 5'- GACACGCAGCTCATTGTAGA -3') amplified a 
150-bp product (2574-2723) and were used as an internal control for comparison with target genes at all time points. Finally, the amplified genes were resolved by electrophoresis and visualized using ethidium bromide staining. (The GenBank accession numbers of the cathepsin B, cathepsin D and actinA3 cDNA are AB045595.1, AY297160.1 and U49854.1, respectively.)

\section{Quantitative real-time RT-PCR}

To compare the influence of hormones (JHA and 20E), BmNPV and temperature on the transcript levels of cathepsin $\mathrm{B}$ and $\mathrm{D}$, the $B$. mori actin $\mathrm{A} 3$ gene was used as the control gene. Real-time PCR was performed in a total reaction volume of $20 \mu \mathrm{l}$, containing $10 \mu \mathrm{l}$ of $1 \times$ SYBR GREEN PCR mix (TaKaRa Code: DRR041A), $1 \mu$ 1:10-diluted cDNA templates and $1 \mu \mathrm{l}$ of each primer $(1 \mu \mathrm{mol} / 1$ actinA3 and $10 \mu \mathrm{mol} / \mathrm{l}$ cathepsin B and cathepsin D), according to the manufacturer's instructions. Reaction conditions were as follows: $94^{\circ} \mathrm{C}$ for $3 \mathrm{~min}$ and 40 cycles of $94^{\circ} \mathrm{C}$ for $5 \mathrm{~s}, 60^{\circ} \mathrm{C}$ for $10 \mathrm{~s}$, and $72^{\circ} \mathrm{C}$ for $10 \mathrm{~s}$. To confirm the amplification of specific products, melting curve cycles continued with the following parameters: $95^{\circ} \mathrm{C}$ for $1 \mathrm{~min}, 55^{\circ} \mathrm{C}$ for $1 \mathrm{~min}$, 80 cycles of $55^{\circ} \mathrm{C}$ for $10 \mathrm{~s}$ and a $0.5^{\circ} \mathrm{C}$ increase per cycle. Amplification and detection of SYBR ${ }^{\circledR}$ Green were performed using MyiQ (Bio-Rad, Hercules, CA, USA). Data were collected as $\mathrm{C}_{\mathrm{T}}$ (PCR cycle number at which fluorescence was detected above the threshold and decreased linearly with increasing target quantity) using the MyiQ optical system software version 1.0 (Bio-Rad). All experiments were performed in triplicate; each sample was run in triplicate on PCR plates, and data were pooled. The $\mathrm{C}_{\mathrm{T}}$ of each sample was used to calculate the $\Delta \mathrm{C}_{\mathrm{T}}$ values (target gene $\mathrm{C}_{\mathrm{T}}$ subtracted from actinA $3 \mathrm{C}_{\mathrm{T}}$ ). The respective mRNA expression data were first normalized to actin $\mathrm{A} 3$ expression to compensate for any difference in reverse transcriptase efficiency. The relative fold change of the mRNA expression of a gene, compared to control, was automatically analyzed by the Opticon Monitor 3, and efficiency was corrected for according to the method of Schefe (2006).

\section{Statistical analysis}

All data were compared by one-way analysis of variance (ANOVA) followed by Tukey's studentisized test when significant differences were found at $P 0.05$ (SAS, 1997). Differences between samplings were considered statistically significant at a probability less than $5 \%$ and marked in figures.

\section{Results}

Cathepsin B and D expression after BmNPV challenge As shown in Fig. 1, the relative expression of mRNA

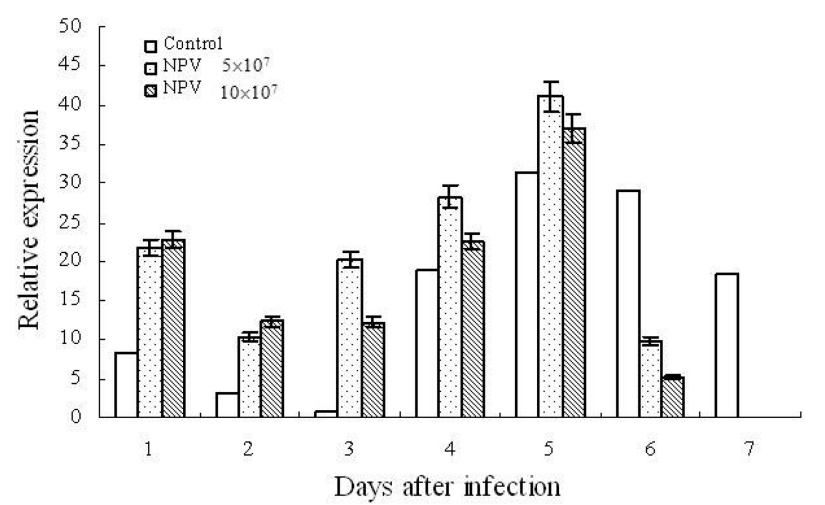

Fig. 1. Expression profile of cathepsin B mRNA in $B$. mori infected by Bombyx mori nuclear polyhedrosis virus (BmNPV). Silkworm larvae on the 1st day of the fifth instar were infected with BmNPV $\left(5 \times 10^{7}\right.$ and $\left.10 \times 10^{7}\right)$. Larval fat bodies were collected at 1-day intervals post-treatment. Each experiment was performed in triplicate. Cathepsin B mRNA expression values were normalized to actin $\mathrm{A} 3$ expression and are shown as the mean \pm S.E. $(n=3)$.

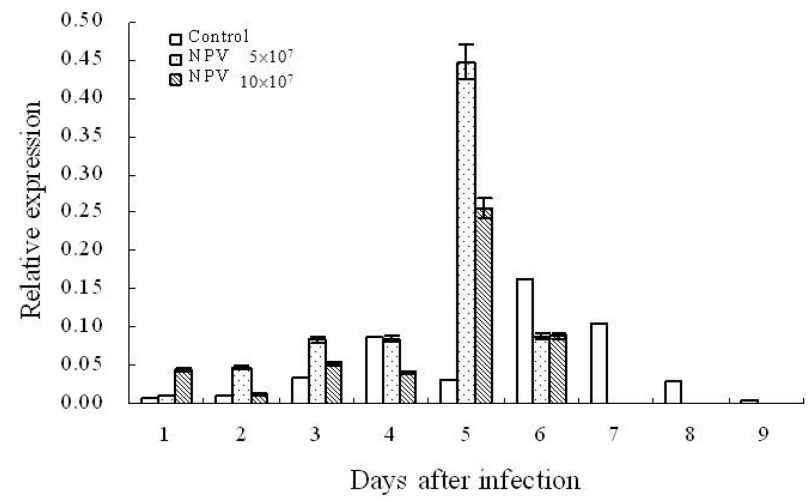

Fig. 2. Expression profile of cathepsin D mRNA in $B$. mori infected by Bombyx mori nuclear polyhedrosis virus (BmNPV). Silkworm larvae on the 1st day of the fifth instar were infected with BmNPV $\left(5 \times 10^{7}\right.$ and $\left.10 \times 10^{7}\right)$. Larval fat bodies were collected at 1-day intervals post-treatment. Each experiment was performed in triplicate. Cathepsin D mRNA expression values were normalized to actin A3 expression and are shown as the mean \pm S.E. $(n=3)$.

encoding cathepsin B was high at day 1 post-infection, then decreased on the next day, and reached its highest level on day 2 before death on day 7. The highest cathepsin B expression in the high BmNPV concentration $\left(10 \times 10^{7}\right.$ polyhedra/ml) group appeared at an earlier time point, compared to results with the lower BmNPV concentration $\left(5 \times 10^{7}\right.$ polyhedra/ml) group (Fig. 1). However, cathepsin $\mathrm{D}$ expression reached its highest level on day 2 before larval death on day 7 in both BmNPV concentration groups, which is similar to cathepsin B (Fig. 2). 
Cathepsin B and D expression after temperature shock The larval span at $25^{\circ} \mathrm{C}$ is 7 days, while higher temperatures shortened the larval span to 6 days, and lower temperatures increased the larval period to 9 days. Cathepsin $\mathrm{B}$ and $\mathrm{D}$ expression varied with development and temperature shock. High temperatures induced cathepsin B expression at both the earlier and later stage, while the moderate and lower temperatures induced cathepsin B expression significantly at the later stage of the $5^{\text {th }}$ instar (Fig. 3). Temperature shock induced increased cathepsin D from 1-day post-treatment, and the expression reached its peak at day 2 before spinning. The influence of the

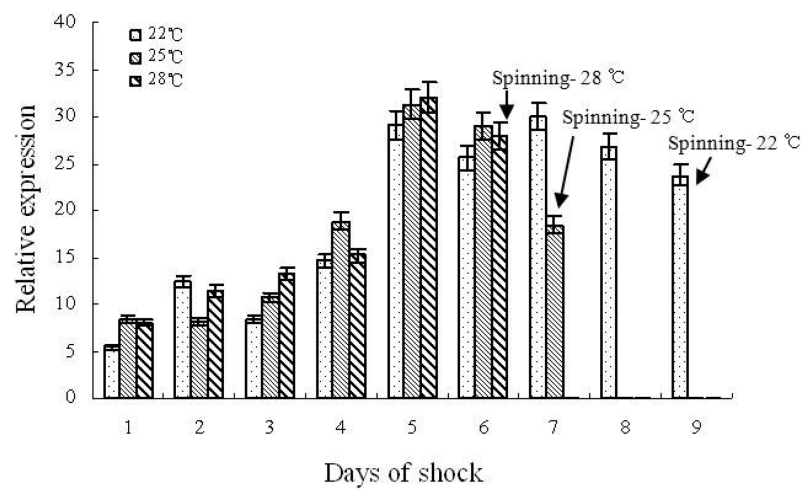

Fig. 3. Expression profile of cathepsin B mRNA in B. mori challenged by temperature. Silkworm larvae were reared at different temperature conditions $\left(22^{\circ} \mathrm{C}, 25^{\circ} \mathrm{C}\right.$ or $\left.28^{\circ} \mathrm{C}\right)$. Larval fat bodies were collected every $24 \mathrm{~h}$. Each experiment was performed in triplicate. Cathepsin B mRNA expression values were normalized to actin A3 expression and are shown as the mean \pm S.E. $(n=3)$.

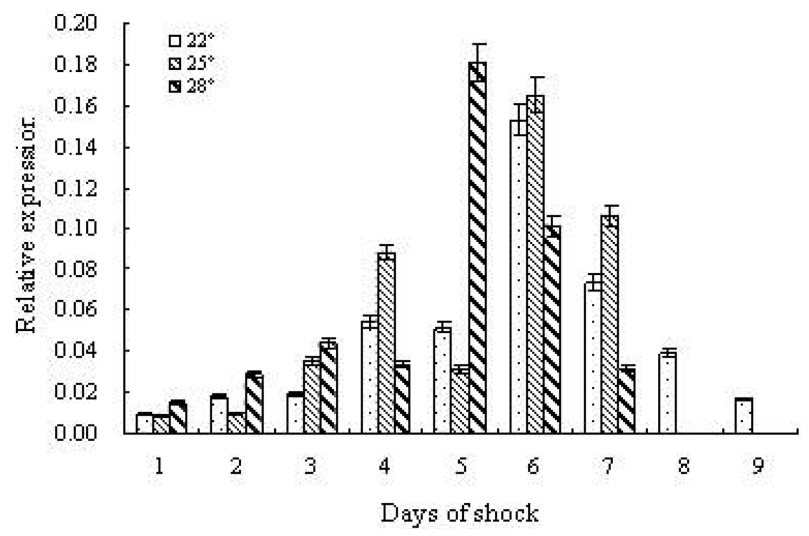

Fig. 4. Expression profile of cathepsin D mRNA in B. mori challenged by temperature. Silkworm larvae were reared at the different temperature conditions $\left(22^{\circ} \mathrm{C}, 25^{\circ} \mathrm{C}\right.$ or $\left.28^{\circ} \mathrm{C}\right)$. Larval fat bodies were collected every $24 \mathrm{~h}$. Each experiment was performed in triplicate. Cathepsin D mRNA expression values were normalized to actin A3 expression and are shown as the mean \pm S.E. $(n=3)$. experimental thermal treatments for cathepsin D expression showed a consistent trend (Fig. 4), i.e. increasing to late stage and reach a peak at $1-2$ days before the end of $5^{\text {th }}$ instar. Comparing the cathepsins, cathepsin B expression is nearly hundred times greater than cathepsin $\mathrm{D}$ expression.

\section{Cathepsin B and D expression after hormone (20E and JHA) challenge}

The results showed that JHA delayed the larval duration 1-2 days, while 20E shortened the larval span by 1 day. There was abundant constitutive expression of cathepsins $\mathrm{B}$ and $\mathrm{D}$ at the mRNA level (Figs. 5 and 6). After larvae were treated with JHA, cathepsin B and D mRNA expression in the fat body was significantly induced; the highest expression appeared at the day before spinning (day 9 of the last instar phase), with a weak decrease in expression at the spinning day (Figs. 5A and 6A). Larvae treated with $20 \mathrm{E}$ also showed enhanced expression of cathepsins B
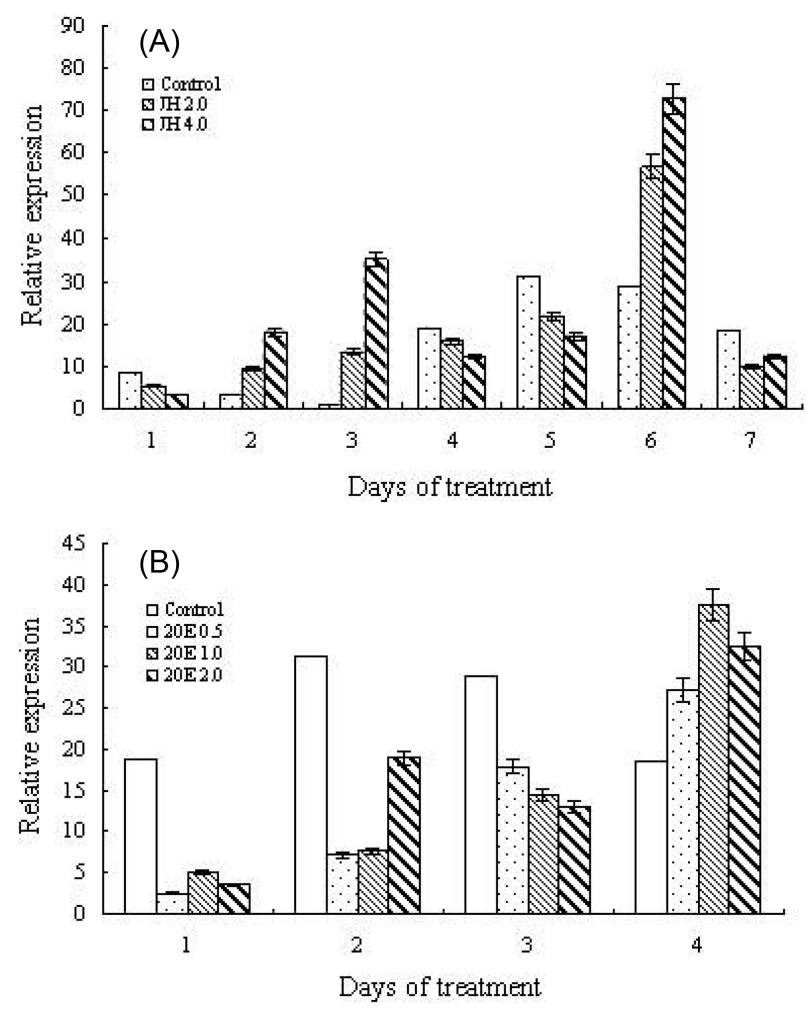

Fig. 5. Expression profile of cathepsin B mRNA in $B$. mori treated with hormones JHA (A) and 20E (B). Silkworm larvae on the $3 \mathrm{rd}$ day of the fifth instar were exposed to JHA $(2.0 \mathrm{mg} / \mathrm{ml}$ and $4.0 \mathrm{mg} / \mathrm{ml})$ or $20 \mathrm{E}(0.5 \mathrm{mg} / \mathrm{ml}, 1.0 \mathrm{mg} / \mathrm{ml}$ and $2.0 \mathrm{mg} / \mathrm{ml})$. Larval fat bodies were collected at 1-day intervals post-treatment. Each experiment was performed in triplicate. Cathepsin B mRNA expression values were normalized to actinA 3 expression and are shown as the mean \pm S.E. $(n=3)$. 

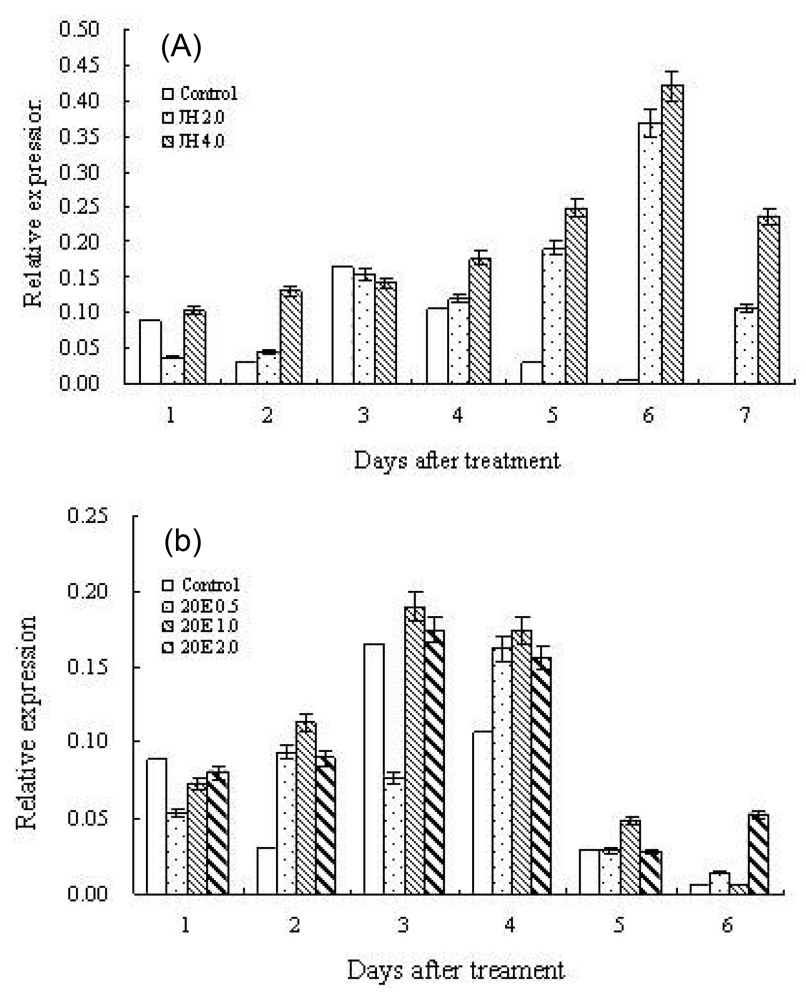

Fig. 6. Expression profile of cathepsin D mRNA in B. mori treated with hormones JHA (A) and 20E (B). Silkworm larvae on the 3rd day of the fifth instar were exposed to JHA $(2.0 \mathrm{mg} /$ $\mathrm{ml}$ and $4.0 \mathrm{mg} / \mathrm{ml})$ or $20 \mathrm{E}(0.5 \mathrm{mg} / \mathrm{ml}, 1.0 \mathrm{mg} / \mathrm{ml}$ and $2.0 \mathrm{mg} /$ $\mathrm{ml}$ ). Larval fat bodies were collected at 1-day intervals posttreatment. Each experiment was performed in triplicate. Cathepsin D mRNA expression values were normalized to actin A3 expression and are shown as the mean \pm S.E. $(n=3)$.

and $\mathrm{D}$, the expression reached a peak at the last day of the $5^{\text {th }}$ instar (Fig. 5B and 6B). The mRNA expression of cathepsins $\mathrm{B}$ and $\mathrm{D}$ exhibited detectable changes posttreatment, and no significant differences were observed between the concentrations used $(2 \mu \mathrm{g} / \mu \mathrm{l}$ and $4 \mu \mathrm{g} / \mu \mathrm{l}$ of JHA, $0.5 \mu \mathrm{g} / \mu \mathrm{l}, 1.0 \mu \mathrm{g} / \mu \mathrm{l}$ and $2.0 \mu \mathrm{g} / \mu \mathrm{l}$ of 20E) (Fig. $5 \mathrm{~A}$ and $6 \mathrm{~A})$.

\section{Discussion}

Cathepsins are expressed in a variety of cells, and cathepsins B and D are among the most abundant lysosomal proteases (Turk et al., 2000). Physiologically, cathepsins degrade proteins nonspecifically inside lysosomes. Expression of cathepsin B and D in insects occurs mostly in fat bodies, oocytes, and hemocytes (Cho et al., 1999; Snigirevskaya et al., 1997).

The larval fat body of $S$. peregrina is degraded during the larval-pupal metamorphosis (Takahashi et al., 1993). Because B. mori undergoes complete metamorphosis, its larval fat body, midgut and silk gland degenerate and are replaced by adult tissues and structures. The involvement of a cathepsin B-like proteinase in fat bodies of the $H$. armigera during pupal-adult metamorphosis has been demonstrated (Yang et al., 2006). Kurata et al. (1992) suggested that a $S$. peregrina cathepsin B-like proteinase could be released from hemocytes when hemocytes contacted the fat body and further degrade the basement membrane of the fat body. $\mathrm{Xu}$ and Kawasaki (2001) observed many hemocytes attaching to the fat body tissues during larval-pupal metamorphosis in B. mori. Hemocytes distributed in such tissues, together with the increased expression of cathepsin B-like proteinase in hemocytes before larva pupation, played a key role in fat body and midgut histolysis during the larval-pupal metamorphosis of $H$. armigera (Yang et al., 2007).

Previously, we showed the expression profile of cathepsin B (Lee et al., 2009) and D (Gui et al., 2006) in the fat body of the silkworm $B$. mori during development and after RNA interference (RNAi)-mediated inhibition. Cathepsin B is induced by 20-OH-ecdysone and is expressed in the fat body of $B$. mori during molting and the larval-pupal and pupal-adult transformations, and its expression leads to programmed cell death. In this study, our results showed relatively higher levels of cathepsin B and D expression after challenge by hormones (JHA and 20E). A high level of expression of cathepsin B and D were observed in the fat body of $B$. mori during an arrest of the larval-pupal transformation. We infer that cathepsin $\mathrm{B}$ and $\mathrm{D}$ participate in fat body apopotosis during B. mori metamorphosis. Insect hemocytes play an important role in larval-pupal metamorphosis and the increase in plasmatocytes and granulocytes before larvae pupation increases the expression of cathepsin B-like proteinase in S. peregrina (Kurata et al., 1992), cathepsin B in B. mori (Xu and Kawasaki, 2001), and cathepsin B-like proteinase in $H$. armigera (Yang et al., 2007).

Cathepsins occur in lysosomes and are also associated with the plasma membrane or are secreted, indicating their role in the digestion of the extracellular matrix (Sloane et al., 1994; Heidtmann et al., 1993). Cathepsins are involved in insect immune responses. In the flesh fly $S$. peregrina, a $26 / 29-\mathrm{kD}$ a protease is specifically released by hemocytes after an immune challenge (Saito et al., 1992), and in Drosophila, cathepsin L protein is induced in the hemolymph of adults after fungal infection (Levy et al., 2004). Transcriptional up-regulation of cathepsin has been reported in immune-stimulated Drosophila and $G$. morsitans morsitans (De Gregorio et al., 2001; Attardo et al., 2006). In this study, we determined that the expression 
of cathepsin B and D was modulated at the transcription level by BmNPV infection. The relative expression of cathepsin B and D was highest on day 2 before death. Serbielle et al. (2009) studied the role of polydnavirus cystatins in the host-parasitoid interaction to characterize Manduca sexta cathepsins (MsCath1 and MsCath2) and revealed that $\mathrm{MsCath} 1$ and $\mathrm{MsCath} 2$ are transcriptionally down-regulated in the course of parasitism. Their results also show that parasitism induces a general increase of cysteine protease activity.

Temperature-induced cathepsin B and D expression increased at the later stage of the $5^{\text {th }}$ instar. Different temperature conditions showed a consistent cathepsin expression trend. We infer that cathepsin B plays a more important role during larval-pupal transformation than cathepsin D.

\section{Acknowledgement}

This work was supported by the National Natural Science Foundation of China grant No. 30972144.

\section{References}

Ahn JE, Zhu-Salzman K (2009) CmCatD, a cathepsin D-like protease has a potential role in insect defens against a phytocystatin. J Insect Physiol 55, 678-685.

Attardo GM, Strickler-Dinglasan P, Perkin SAH, Caler E, Bonaldo MF, Soares MB, El-Sayeed N, Aksoy S (2006) Analysis of fat body transcriptome from the adult tsetse fly, Glossina morsitans morsitans. Insect Mol Biol 15, 411-424.

Boldbaatar D, Sikasunge CS, Battsetseg B, Xuan X, Fujisaki K (2006) Molecular cloning and functional characterization of an aspartic protease from the hard tick Haemaphysalis longicornis. Insect Biochem Mol Biol 36, 25-36.

Brunelle F, Nguyen-Quoc B, Cloutier C, Michaud D (1999) Protein hydrolysis by Colorado potato beetle, Leptinotarsa decemlineata, digestive proteases: the catalytic role of cathepsin D. Arch Insect Biochem Physiol 42, 88-98.

Carnevali O, Mosconi G, Cambi A, Ridolfi S, Zanuy S, Polzonetti-Magni AM (2001) Changes of lysosomal enzyme activities in sea bass (Dicentrarchus labrax) eggs and developing embryos. Aquaculture 202, 249-256.

Cho WL, Raikhel AS (1992) Cloning of cDNA for mosquito lysosomal aspartic protease-sequence-analysis of an insect lysosomal-enzyme similar to cathepsin D and E. J Biol Chem 267, 21823-21829.

Cho WL, Tsao SM, Hays AR (1999) Mosquito cathepsin Blike protease involved in embryonic degradation of vitellin is produced as a latent extraovarian precursor. J Biol Chem 274, 13311-13321.

De Gregorio E, Spellman PT, Rubin GM, Lemaitre B (2001)
Genome-wide analysis of the Drosophila immune response by using oligonucleotide microarrays. Proc Nat Acad Sci USA 98, 12590-12595.

Duve C (1983) Lysosomes revisited. Eur J Biochem 137, 391397.

Fehrenbacher N, Jaattela M (2005) Lysosomes as targets for cancer therapy. Cancer Res 65, 2993-2995.

Gui ZZ, Lee KS, Kim BY, Choi YS, Wei YD, Choo YM, Kang PD, Yoon HJ, Kim I, Je YH, Seo SJ, Lee SM, Guo XJ, Sohn HD, Jin BR (2006) Functional role of aspartic proteinase cathepsin D in insect metamorphosis. BMC Dev Biol 6, 49.

Gui ZZ, Hou CX, Liu T, Qin G.X, Li MW, Jin BR (2009) Effects of insect viruses and pesticides on glutathione Stransferase activity and gene expression in Bombyx mori L. J Econ Entomol 102, 1591-1598.

Heidtmann HH, Salge U, Havemann K, Kirschke H, Wiederanders B (1993) Secretion of a latent, acid activatable cathepsin L precursor by human non-small cell lung cancer cell lines. Oncol Res 5, 441-451.

Kurata S, Saito H, Natori S (1992) The 29-kDa hemocyte proteinase dissociates fat body at metamorphosis of Sarcophaga. Dev Biol 153, 115-121.

Lee KS, Kim BY, Choo YM, Yoon HJ, Kang PD, Woo SD, Sohn HD, Roh JY, Gui ZZ, Je YH, Jin BR (2009) Expression prole of cathepsin B in the fat body of Bombyx mori during metamorphosis. Comp Biochem Physiol B 154, 188-194.

Metcalf P, Fusek M (1993) Two crystal structures for cathepsin $\mathrm{D}$ : the lysosomal targeting signal and active site. EMBO J 12, 1293-1302.

Nakagawa T, Roth W, Wong P, Nelson A, Farr A, Deussing J, Villadangos JA, Ploegh H, Peters C, Rudensky AY (1998) Cathepsin L: critical role in Ii degradation and CD4 T cell selection in the thymus. Science 280, 450-453.

Nakanishi H, Zhang J, Koike M, Nishioku T, Okamoto Y, Kominami E, Figura K, Peters C, Yamamoto K, Saftig P, Uchiyama Y (2001) Involvement of nitric oxide released from microglia-macrophages in pathological changes of cathepsin D-decient mice. J Neurosci 21, 7526-7533.

Rabossi A, Stoka V, Puizdar V, Turk V, Quesada-Allue LA (2004) Novel aspartyl proteinase associated to fat body histolysis during Ceratitis capitata early metamorphosis. Arch Insect Biochem Physiol 57, 51-67.

Saftig P, Hetman M, Schmahl W, Weber K, Heine L, Mossmann H, Köster A, Hess B, Evers M, Figura K (1995) Mice decient for the lysosomal proteinase cathepsin D exhibit progressive atrophy of the intestinal mucosa and profound destruction of lymphoid cells. EMBO J 14, 35993608.

Schefe JH, Lehmann KE, Buschmann IR, Unger T, Funke-Kaiser H (2006) Quantitative real-time RT-PCR data analysis: current concepts and the novel "gene expression's $C_{T}$ difference" formula. J Mol Med 84, 901-910

Serbielle CI, Moreau S, Veillard F, Voldoire E, Annie B, Mannucci MA, Volkoff AN, Drezen JM, Lalmanach G, Huguet E (2009) Identification of parasite-responsive cysteine pro- 
teases in Manduca sexta. Biol Chem 390, 493-502.

Shiba H, Uchida D, Kobayashi H, Natori M (2001) Involvement of cathepsin B- and L-Like proteinases in silk gland histolysis during metamorphosis of Bombyx mori. Arch Insect Biochem Physiol 390, 28-34.

Shompole S, Jasmer DP (2001) Cathepsin B-like cysteine proteases confer intestinal cysteine protease activity in Haemonchus contortus. J Biol Chem 276, 2928-2934.

Silva CP, Xavier-Filho J (1991) Comparison between the levels of aspartic and cysteine proteinases of the larval midguts of Callosobruchus maculatus (F) and Zabrotes subfasciatus (Boh) (Coleoptera, Bruchidae). Comp Biochem Physiol B 99, 529-533.

Sloane BF, Moin K, Sameni M, Tait LR, Rozhin J, Ziegler G (1994) Membrane association of cathepsin B can be induced by transfection of human breast epithelial cells with c-Harasoncogene. J Cell Sci 107, 373-384.

Snigirevskaya ES, Hays AR, Raikhel AS (1997) Secretory and internalization pathways of mosquito yolk protein precursors. Cell Tissue Res 290, 129-142.

Takahashi N, Kurata S, Natori S (1993) Molecular cloning of cDNA for the $29 \mathrm{kDa}$ proteinase participating in decomposition of the larval fat body during metamorphosis of Sarcophaga peregrina (flesh fly). FEBS Lett 334, 153-157.

Tsuji H, Akasaki K (1994) Identification and characterization of lysosomal enzymes involved in the proteolysis of phenobarbital- inducible cytochrome P450. Biol Pharm Bull 17, 568-571.
Turk B, Turk D, Turk V (2000) Lysosomal cysteine proteases: more than scavengers. Biochim Biophys Acta 1477, 98-111.

Urbich C, Heeschen C, Aicher A, Sasaki K, Bruhl T, Farhadi MR, Vajkoczy P, Hofmann WK, Peters C, Pennacchio LA, Abolmaali ND, Chavakis E, Reinheckel T, Zeiher AM, Dimmeler S (2005) Cathepsin L is required for endothelial progenitor cell-induced neovascularization. Nat Med 11, 206213.

Xu YS, Kawasaki H (2001) Isolation and expression of cathepsin B cDNA in hemocytes during metamorphosis of Bombyx mori. Comp Biochem Physiol B 130, 393-399.

Yang XM, Hou LJ, Dong DJ, Shao HL, Wang JX, Zhao XF (2006) Cathepsin B-like proteinase is involved in the decomposition of the adult fat body of Helicoverpa armigera. Arch Insect Biochem Physiol 62, 1-10.

Yang XM, Hou LJ, Wang JX, Zhao XF (2007) Expression and function of cathepsin B-like proteinase in larval hemocytes of Helicoverpa armigera during metamorphosis. Arch Insect Biochem Physiol 64, 164-174.

Zhong D, Katar M, Linebaugh BE, Sloane BF, Berk RS (2001) Expression of cathepsins B, D and L in mouse corneas infected with Pseudomonas aeruginosa. Eur J Biochem 268, 6408-6416.

Zou FM, Lou DS, Zhu YH, Wang SP, Jin BR, Gui ZZ (2011) Expression profiles of glutatione S-transferase (GST) genes in larval midgut of Bombyx mori exposed to insect hormones. Mol Biol Rep 38, 639-647. 